\title{
INFÂNCIA E MEMÓRIA EM ONDJAKI: VOANDO PELO TEMPO
}

\author{
Izabel Cristina da Rosa Gomes dos Santos \\ (Universidade Federal de Santa Catarina)
}

\section{RESUMO}

As palavras que seguem, neste artigo, esquadrinham possíveis fios existentes entre o narrador de memórias de infância e a escrita ficcional, no sentido de perceber aspectos ficcionais no relato memorialístico. Assim, propõe analisar o tecido narrativo de Os da minha rua, do escritor angolano Ondjaki, a fim de compreender como se configura as relações entre o vivido e o escrito, entre o tempo e a experiência, dos quais interdepende a vivência humana. Nesses desdobramentos o escritor mescla, sob o espaço da infância, memórias e passados imaginados, conduzindo para uma leitura intimista e deixando ao leitor a eleição de estatuto autobiográfico ou não. Essa escrita remete para o lugar da infância, do inventado e do vivido, no qual o olhar infantil rege as memórias lapidando-se em uma linguagem poética, colorida e sinestésica. Nessas tessituras a voz do menino-narrador - que não necessariamente é o autor - aproxima-se da memória e reinventa histórias dos possíveis vividos em Angola, pois assim como na infância, as histórias acontecem em momentos não cronológicos, sejam elas verdadeiras ou não.

PALAVRAS-CHAVE: memória, infância, Ondjaki.

\section{ABSTRACT}

The words that follow analizies the interrelation between narrators of childhood memories and narrators fictional writing, in order to realize the aspects fictionals. Thus, the article propose to analyze the narrative aspect of Os da minha rua, of Angolan writer Ondjaki in order to understand how it configures the relationships between the lived and written. These unfolding the writer mixes the understand about the space and time childhood and imagined past, leading to an intimate reading and allowing the reader the with the election of autobiographic or not status. This writing refers to time and space of childhood, the invented and lived, in which the memories conducts to a poetic, colorful and high level of sensibility language. On these writing process the voice of child-narrator - that not necessary is the writer - get closer of memory and reinvent histories of possible lived facts in Angola, the stories take place in non-chronological moments, whether true or not.

KEYWORDS: memory, childhood, Ondjaki. 


\section{INÍCIO DE CONVERSA...}

A escrita, aqui apresentada, assume um caráter de encontro com a palavra, com a infância vertida em palavra e em afinidades. Assim, o tecido narrativo da infância e a produção de Os da minha rua do escritor angolano Ondjaki, ${ }^{1}$ serão o aporte dessa análise para firmar uma escrita que entrecruze literatura africana e infância, ${ }^{2}$ e componha "a recomendação de uma leitura que não busca compreender exatamente o que o autor queria dizer, mas que se constitui bem mais como experiência, como exercício consigo mesmo." (FISCHER, 2005, p. 125)

As palavras, portanto, movem um pensar em busca de compreender o que, de fato, a infância (nos) ensina. Seguindo, nesse lugar ${ }^{3}$ de encontro entre infância e literatura, vale anunciar a ancoragem nos estudos da infância que propõem construir um educar potencializado para pensar o mundo, permitindo ver a novidade que as crianças trazem consigo, aceitando o risco do desconhecido e do inusitado, e, assim, redimensionar as práticas cotidianas nos contextos educacionais, pois "talvez tenha chegado o momento de aprendermos com as crianças o que a infância tem a nos dizer. Talvez a infância, assim como a poesia, não precise ser analisada, mas sentida”. (LEAL, 2004, p. 22)

Assim, ouvir e ver as crianças parte do conceito de que elas (as crianças) trazem a capacidade de estrear o mundo e reinventá-lo a sua maneira, quase sempre pautadas em uma logicidade própria, intensa e plena de soluções. Tornando-se fundamental um diálogo com a pluralidade da infância, sob uma perspectiva reflexiva dos possíveis fios existentes entre um narrador de memórias de infância e sua escrita ficcional, no sentido de analisar as variações entre o ocorrido e o narrado, ou seja, os aspectos ficcionais no relato memorialístico.

\section{MEMÓRIA (RE)VELADA EM ONDJAKI}

Esse lugar de encontro literário com uma infância de matriz africana desdobrada em palavra, banhada por imagens, revela-se pela escrita de Ondjaki, que, nascido sob o céu angolano de Luanda em 1977, teve a infância experienciada entre as ruas da cidade, no bairro de Alvalade, crescendo entre amigos e família, entre os da rua, os da casa, pessoas que, segundo o autor, "povoam agora os meus livros com uma ternura que eu quero ver transformada em literatura. E essa infância de 'todos nós', aconteceu em Luanda, nos anos 80. Diferente, portanto, do que terá sido a infância de outras crianças no Huambo, Kuíto ou Luena." (ONDJAKI, maio/2008)4

E diante de Os da minha rua, ressalto a acuidade com que as crianças circundam a obra e a presença das relações entre memória e infância como recurso literário do autor, que revela: "além de as convocar (as memórias), gosto de ser assaltado por memórias. Mantêm-me desperto, atento e trazem-me ao quotidiano uma certa magia”. (ONDJAKI, maio/2008). ${ }^{5}$ 
Portanto, merece atenção a relação intrínseca entre memória coletiva e individual, tema que interessa aos estudos filosóficos há séculos, transpassa diferentes sociedades e a elas se enraíza. Assumindo a condição de que a memória envolve genealogias indissolúveis ao sentimento do tempo como algo que escoa pelas mãos (CHAUÍ, 1998), há de se compreender a memória não somente como instrumento para arquivar momentos, mas, sobretudo, como capacidade de (re)significar as coisas e a si próprio, implicando diretamente a visão acerca das reconfigurações do vivido, afinal "não temos nada melhor que a memória para significar que algo aconteceu, ocorreu, se passou antes que declarássemos lembrar dela." (RICOEUR, 2007, p.40)

Igualmente, sendo a memória uma construção feita no presente a partir do vivido, é nos estudos de Maurice Halbwachs (1990) que se tem uma grande contribuição para o entendimento do que é e como se articula esse mecanismo que, mesmo aparentemente individual, remete, na maioria das vezes, a um grupo. É nesse movimento entre individual e coletivo que a memória norteia o sujeito no percorrer de suas lembranças, interagindo com o coletivo (grupo ou sociedade) em que já está inserido. E segue alterando-se conforme o lugar ocupado e as relações mantidas com o meio. Esse lembrar envolve um emaranhado de experiências vividas, por si e pelos outros, nutridas pelas memórias de um coletivo, porque nossas lembranças "nos são lembradas pelos outros, mesmo que se trate de acontecimentos nos quais só nós estivemos envolvidos, e com objetos que só nós vimos. É porque, em realidade, nunca estamos sós." (HALBWACHS, 1990 , p. 26) Revela-se, do mesmo modo, a ideia de grupo no qual nos relacionamos e a confirmação de que através desse coletivo nos deparamos com outras ideias e modos de pensar. Essa memória construída/lembrada a partir das contribuições de um coletivo possibilita compreender que, no processo de rememorar, o outro é constitucional, e irrompe em nossas vidas sem pedir licença (SKLIAR, 2003). E assim, apreender que esse outro, além de construir a memória coletiva, constitui toda uma relação de encontro com o mundo, induz a refletir que

estar-junto e entre-com-os-outros nos faz dobrar, multiplicar formas estéticas de convivência, nos faz sentir e vibrar a presença do outro, sem ter a preocupação em hospedá-lo, colocá-lo em algum lugar. $\mathrm{O}$ encontro pressupõe presenças em trânsito, entre-lugares, nomadismo. (LIMA, 2008, p. 119)

Partindo do outro que me habita, é essencial considerar os relevos entre tempo e memória individual e coletiva, atentando-se para as relações entre o tempo e a experiência, entre memória autobiográfica (mais densa e contínua) e memória histórica (mais ampla). Nesses contornos ampara-se a palavra, ou melhor, as escolhas do escritor. A palavra assume aspectos ficcionais no relato memorialístico, pois o sujeito-escritor apresenta distanciamentos e aproximações do vivido. Isso equivale a fazer (ou não) alguns pactos de leitura (autobiográfico ou romanesco) ${ }^{6}$ com o tecido narrativo de 
Ondjaki que evoca, sob o espaço da infância, algumas reconstruções e 'impressões' de memória. Esse movimento não linear produz modificações, e quando interligados ao imaginário e ao poético resulta em uma ficção. (SOUZA, 2001)

De tal modo, na obra Os da minha rua, Ondjaki apresenta indícios de possíveis deslocamentos, entre retrospectivas ou prospectivas, para reorganizar os acontecimentos na medida em que transita entre passado e presente, de onde aparentemente busca preencher o vazio do tempo que passou colorindo lembranças inventadas. Talvez essa escrita seja um colorir experiências, mesclando memórias e inventando passados, conduzindo para uma leitura mais intimista, mais próxima, deixando ao leitor a eleição de estatuto autobiográfico ou não. As escolhas de Ondjaki remetem para o lugar de sensibilidade da infância, do inventado e do vivido, fazendo do texto um híbrido entre o memorialístico e as invenções que partem do passado. (CHAVES, 2004)

Nessa busca do equilíbrio entre o tempo vivido e o tempo ficcionado, o olhar infantil rege as memórias lapidando-se em uma linguagem poética, colorida e sinestésica, e transformando a leitura em uma experiência ampliada pelo prisma da (i)logicidade das infâncias. ${ }^{7}$

A análise dessas imagens literárias desvela a não classificação autobiográfica das obras, além de um enfoque narrativo preocupado com a verossimilhança e não com a veracidade dos fatos. Assim, por meio da ficção, a voz do menino-narrador - que não necessariamente é o autor - aproxima-se da memória e reinventa histórias dos possíveis vividos em Angola.

Esse desdobrar literário apresenta-se como convite para situar dois tempos: o tempo khrónos (sequencial, sucessivo) e o tempo aión (temporalidade não numerável, não sucessiva, intensa e qualitativa). Prontamente, esse menino-narrador, presente na obra, oferece ao leitor uma temporalidade aiônica, ou seja, descontínua, durativa e intensiva, que "habita a temporalidade do acontecimento, da experiência, da interrupção da linearidade histórica em busca de um novo começo." (KOHAN, 2010, p. 132) Articular o conceito de infância, revelado nas páginas de Os da minha rua, exige investigar as vozes no cerne de alguns contos da obra, a partir do movimento de sair do lugar ocupado pelo adulto e aprofundar-se no território da infância e de seus múltiplos e simultâneos lugares: interações, convívios, mediações, culturas e tempos de aprendizagem. Compõe-se, assim, um desafio de escrita, talvez porque não se conheça em profundidade a dinamicidade com que as crianças se movimentam e se mobilizam através de seus modos de ver e entender o mundo. Talvez porque ainda nos causa estranhamento enxergar a criança em seus silêncios e em sua maneira específica de 'desenhar' seus lugares e sua história. Portanto, o desafio incide na busca de palavras que revelem esse lugar (in)explorado e saturado pelos discursos que dizem conhecer a infância. E de tal modo, minha tentativa de escrita procura afirmar 
palavras que tornem visível essa outra infância invisível e, a partir dessa nova visibilidade, permitam encontrar um novo lugar para a infância na palavra e no pensamento, a infância de um novo lugar para pensar e escrever nos espaços educacionais. (KOHAN, 2010, p. 128)

Compreendo que esquadrinhar na obra de Ondjaki o lugar da infância é desprender-se da logicidade adulta e permitir a sutileza das vozes infantis por vezes silenciadas, por vezes esquecidas, por vezes sobrepostas por vozes adultas. Assim, fica o convite para um pequeno deambular entre crianças que circulam algumas obras ${ }^{8}$ de Ondjaki.

\section{PELAS MÃOS DAS CRIANÇAS EM ONDJAKI}

Deambular pelas ruas de Luanda, através da escrita de Ondjaki, é percorrer uma cartografia de amizade, afetos e parceria. Em uma primeira visita, vale registrar que as crianças da rua Fernão Mendes Pinto, do bairro da Praia Do Bispo e da escola Mutu Ya Kevela, têm muito a partilhar, a contar suas relações com o mundo. Portanto, antes de abrir as primeiras páginas de $\mathrm{Os}$ da minha rua, considero importante uma breve apresentação das crianças que são celebradas nos enredos, revelando-se em uma "cartografia de trajetos, de intensidades, de densidades, ou seja, uma cartografia inventada por uma constelação de afectos (sic)." (CAMPOS; LIMA, 2012, p. 149-150) $)^{9}$.

Portanto, em celebração da amizade e afetos, importa apresentar Jika, o mais novo da rua, parceiro de aventuras arriscadas. E ainda o Bruno, dono dos calções verdes e dado a confusões na escola; o Murtala que comia exageradamente na casa dos outros; o Pinduca (Pi, ou 3,14); o Jorge Tem Calma, o Paulinho, o Gadinho e os agitadores da turma: Célio, Claudio, Filomeno, Kalí e o Hélder. Entre as meninas, tem-se a curiosa Petra, a bonita Romina, Charlita (e suas irmãs), Nucha, Isabel, Aina, Luaia, Isaura e Rafaela. Nesses núcleos, a turma da oitava classe possuía seus apelidos: Serpente, Cabrito, Pacaça, Barata-da-Sibéria, a Joana Voa-Voa, a Gazela, o É-te, o Agostinho-Neto, o Sucubidú, e o Jacó, atribuído ao narrador, falador compulsivo. (ONDJAKI, 2007, p. 132)

Caminhar entre essas crianças, é também conhecer diferentes infâncias, construções de vidas partilhadas pela amizade. É rever a ideia de que "os adultos pensam que a 'nossa vida é só brincar'. Não é bem assim." (ONDJAKI, 2009, p. 31) Nesses diferentes cotidianos, conheci a vida de Charlita "que tinha óculos grossos, amarelos e feios" (ONDJAKI, 2007, p. 39). Ela e as irmãs, igualmente míopes, partilhavam o mesmo par de lentes (óculos) na hora da telenovela, "cada uma via dois minutos e os óculos mudavam de rosto." (ONDJAKI, 2007, p. 39), isso acontecia porque a família não tinha condições financeiras para propiciar óculos para todas. E mesmo assim, Charlita preserva o riso porque "[...] ria de ser a única da casa que conseguia ver bem as telenovelas e os sorrisos nas bocas nítidas de todas as personagens." (ONDJAKI, 2007, p. 39) 
E ainda, a vida do 3,14 também tinha tarefas em casa e na venda do avô. Quanto à vida do Gadinho

também nem sempre era fácil com essas coisas de aturar tudo o que ele não podia fazer: não podia brincar, não podia fazer festa de anos, nem podíamos lhe dar prendas, nem podia vir às nossas festas de anos e nem mesmo a prenda que todos juntamos para lhe dar o pai dele não aceitou. (ONDJAKI, 2009, p. 32)

Nesse caminhar entre crianças, a chuva fina trouxe-me a imagem do Murtala, em sua casa tão pequena para tantas pessoas, porque quando chove só dormem sete de cada vez, "os outros cinco esperam todos encostados na parede onde há um tectozinho que lhes protege. [...] Sempre que chove de noite, o Murtala, no dia seguinte, dorme nos três primeiros tempos." (ONDJAKI, 2006, p. 137)

Penso na vida do Paulinho, que era particularmente complicada, porque além da ajuda em casa "sempre a acartar água porque a maior parte das vezes não havia”, ele também ajudava na oficina mecânica do pai carregando peças pesadas. E ainda tinha que treinar judô e "cair e a levar porrada sem reclamar do mestre nem dos colegas" (ONDJAKI, 2009, p. 36).

Esse deambular leva a refletir acerca das diferentes vidas que se configuram nos contextos infantis, o quanto é preciso apreender suas práticas sociais e, especialmente, o quanto "essa cartografia oferece a leitura reveladora capaz de descortinar a força e a resistência do afeto, e entre trajetos e territórios." (CAMPOS; LIMA, 2012, p.149-150) ${ }^{10}$. Para, quem sabe, ampliar as discussões que envolvem esses sujeitos-crianças. Assim, convido para o encontro com o menino narrador (Menino N) em Os da minha rua.

\section{A INFÂNCIA E O MENINO N}

Percorrer a obra de Ondjaki é, também, um convite para possíveis leituras: apresento o pacto de leitura acerca do Menino N, que pode ser considerado Menino Narrador, ou Menino Ndalu (Ondjaki). Isso é uma escolha de quem lê, mas prossigamos...

O Menino $\mathrm{N}$ conduz a uma viagem de experiência, sempre em primeira pessoa, com verbos no pretérito e sob o ritmo da oralidade. Decompõe espaço/tempo em narrativas curtas, instala o cenário de uma entre tantas infâncias possíveis em Luanda: a rua, a escola, os amigos, o arranjo familiar, professores, despedidas, amores, cores, cheiros e histórias.

Importa, aqui, buscar os enlaçamentos que o Menino $\mathrm{N}$ desvela em cada narrativa da obra Os da minha rua, entre o seu vivido e as suas invencionices. Almeja-se, à guisa de convite, seguir pelas sendas dessa memória construída e inventada pela palavra, na tentativa de

Perceber que essa palavra eclode em múltiplos sentidos, nos põe como tarefa pensar nessa experiência que pode desdobrar-se num enigma seguido por infinitos deslizamentos 
conceituais. Pensar [...] e conhecer o que ainda não conhecemos, de saber o que ainda não sabemos. (CAMPOS; LIMA, 2012, p.149-150) ${ }^{11}$ grifos meus.

Deste modo, segue uma leitura que já no conto de abertura "O voo do Jika" (p. 17), acontece primeiro chamamento ao leitor: saltar com o Menino N e com o amigo Jika de um telhado, relativamente baixo, usando um guarda-chuva como paraquedas.

Lá embaixo estava a relva verde do jardim. O Jika abriu um muito, muito pequenino guarda-chuva azul.

- Põe a mão aqui - ensinou-me - Agora podemos saltar.

- Tens a certeza? - olhei para baixo.

- Vamos só.

Saltamos.

A infância é uma coisa assim bonita: caímos juntos na relva, magoamo-nos um bocadinho, mas sobretudo rimos.(ONDJAKI, 2007, p. 19)

Essa cena, desprendida das tantas acrofobias (físicas e emocionais) que os adultos cultivam, apresenta o tom da leitura que se segue: subverter a lógica do cotidiano e especialmente do riso, fazendo com que o leitor possa construir um pensar que ressoe o riso. (LARROSA, 2003) Aponta essa cena para o riso que dialoga "com o sério, que dança com o sério; ou melhor, desse riso que faz dialogar o sério, que o tira de seus esconderijos, que o rompe, que o dissolve, que o coloca em movimento, que o faz dançar". (LARROSA, 2003, p. 169) E igualmente seguirá essa leitura, sob flashes do experenciado em Os da minha rua, buscando um habitar no riso e na infância.

No encontro peculiar das sensações e da franqueza, sucede a narrativa "A televisão mais bonita do mundo" (p. 21), em que o Menino N, levado pelo Tio Chico para a casa do amigo Lima, conhece uma televisão colorida. A experiência imagética impede-o de calar diante do que vê, e expressa no auge de uma sinceridade sem receios: “Chéeeeeee, essa televisão é bem esculú, e todos riram do meu espanto assim sincero: era a primeira televisão a cores que eu via na minha vida." (ONDJAKI, 2007, p. 25) ${ }^{12} \mathrm{E}$, a partir de imagens coloridas nessa televisão, bonita como uma aquarela, ele encanta-se com o que vê e fica a pensar se os primos acreditariam nas cores exageradas da televisão do Lima. O episódio envolve um encantamento que o permite expressar seu sentimento sem receio da reação dos adultos, que também aparece na opinião do Menino $\mathrm{N}$ sobre as mobílias que o Lima vendia: "Eu não gostava dos móveis que o Lima vendia, mas aquelas cadeiras até que eram fixes, ${ }^{13}$ pintadas de uma cor clara com fitas assim de um plástico verde" (ONDJAKI, 2007, p. 23, grifos meus).

Esse modo de inventariar o mundo, de encontrar soluções e dizer o que vê e sente sem medo multiplica-se na certeza de "que a importância de uma coisa há que ser medida pelo encantamento que a coisa produza em nós.” (BARROS, 2006, s.p.) 
Embora o Menino $\mathrm{N}$ traceje um cotidiano sensorial repleto de cores e cheiros, inundado por uma linguagem lírica, ele também é tomado por algumas dores, perdas e despedidas.

O relato de perda em "O portão da casa da tia Rosa" (p. 95) apresenta-se cingido pelo choro do Menino N: "se me sacudissem podiam cair mais lágrimas" (ONDJAKI, 2007, p.98). Nesse conto, com o desaparecimento da tia Rosa e do tio Chico, a angústia toma conta do menino, especialmente pelo silêncio que invadiu a casa: "Mas não me apetecia estar ali sem a tia Rosa e sem o tio Chico. Olhei o pequeno lago quase na saída, e também não vi os cágados. Nem vozes, nem barulhos de vizinhança. Nada." (ONDJAKI, 2007, p. 98).

Essas imagens intensificam-se no enredo, especialmente no choro contido (e por que não sentido?), na interferência do adulto (professora) dentro do espaço da instituição educativa e nas manifestações infantis de escrita e leitura. Em um desses quadros narrativos, "Os calções verdes do Bruno” (p. 101), o Menino N revela o gesto velado de uma carta amorosa do colega Bruno para Romina: "Ainda por cima de noite só sonho com os caracóis de teus cabelos tipo cacho de uva” (ONDJAKI, 2007, p. 102) A cena acontece na instituição Mutuyakevela e tem uma intervenção abrupta do adulto, mesmo sendo uma pura manifestação da escrita, mesmo sendo "uma das cartas de amor mais bonitas que ia ler na minha vida, e eu próprio, anos mais tarde, ia escrever uma carta de amor também muito bonita, mas nunca tão sincera como aquela" (ONDJAKI, 2007, p. 103). A situação finda com a carta rasgada pela professora em pedaços pequeninos, assim como as lágrimas de Bruno e do Menino N, ou seja, evidencia-se o silenciamento imposto por uma concepção adultocêntrica. Pontua-se, aqui, que essas concepções, são "práticas centradas nos interesses dos adultos, mas destinadas à criança e ao adolescente, sem ouvi-los; exteriores aos desejos do outro, aos seus saberes". (SOUSA, 2010, p. 25)

Outro quadro de silenciamento também se observa no conto "Bilhete com foguetão" (p. 85), quando o Menino N conta sua experiência com o bilhetinho para Petra, menina bela e dona de uma mochila colorida que lhe chamava a atenção. O Menino N, só com olhos para Petra, passa o intervalo da aula tentando escrever um bilhete com desenho de um foguete para dizer que ela tinha "um estojo bonito com cores de Carnaval da Vitória e a mochila também, pele tipo mousse de chocolate e uns olhos que, de longe, pareciam duas borboletas quietas e brilhantes." (ONDJAKI, 2007, p. 87) No entanto, Marisa, sua colega de carteira, entrega o bilhete para a delegada da turma, que lê, debocha do menino num gesto de autoritarismo e sob o silêncio do constrangimento ele abafa as lágrimas e a humilhação: "cruzei os braços na carteira, escondi a cabeça, fechei os olhos, e pelos risos eu ia entendendo o que se passava ali." (ONDJAKI, 2007, p. 87)

Nesses dois eventos narrativos, vale ressaltar que se a infância tem domínio da imaginação e da reinvenção das coisas, seria, talvez, o momen- 
to de refletir sobre a postura dos adultos que convivem com as crianças, especialmente, em que medida a intervenção e o discurso não são pautados em uma convenção adultocrática, ou seja, tomados pelo "discurso que faz valer a palavra e as concepções do adulto; que submete o outro, nesse caso a criança e o adolescente, aos olhares e às práticas considerados pelos adultos adequados para eles" (SOUSA, 2010, p. 27).

Pergunto-me, no que se refere às práticas cotidianas em contextos de educação, quanto que, em nome da ordem, não se atropela as condições aiônicas vividas pelos sujeitos-criança que transitam nesses espaços-tempos de infância? Afinal, a imaginação infantil "trabalha subvertendo a ordem estabelecida, pois, impulsionada pelo desejo e pela paixão, ela está sempre pronta para mostrar uma outra possibilidade de apreensão das coisas, do mundo e da vida. (SOUZA, 1994, p. 149)

Outra experiência do Menino N com o envolvimento da leitura aparece em "Nós choramos pelo Cão Tinhoso" (ONDJAKI, 2007, p. 131, grifos meus), em que ele é convocado a ler o tenso conto "Nós matamos o Cão Tinhoso", do escritor moçambicano Luis Bernardo Honwana. ${ }^{14}$ A relação da leitura é de entrega e emoção, tanto pelo que diz o texto, como pelo movimento da leitura profunda que envolve aquela sala de aula. $\mathrm{O}$ Menino N, já conhecia o conto, "sabia que aquele texto era duro de ler. Mas nunca pensei que umas lágrimas pudessem ficar tão pesadas dentro de uma pessoa" (ONDJAKI, 2007, p. 99). Por conseguinte, sentia a tensão crescente das feridas penduradas do cão, da Isaura que amava o Tinhoso e dos tiros mortíferos do fim do conto. Mesmo conhecendo o enredo, quase não segura as lágrimas e arrasta-se de tal forma nesse fluxo de leitura, estabelecendo a ideia de que ler é "recolher o que se vem dizendo para que se continue dizendo outra vez [...] como sempre se disse e como nunca se disse, numa repetição que é diferença e numa diferença que é repetição." (LARROSA, 2003, p. 141)

A relação com o tempo é, também, evidenciada em "O último Carnaval da Vitória” (p. 59) abordado sob a perspectiva do tempo aión (durativo e intenso): "vivíamos num tempo fora do tempo [...] Para nós segunda-feira era um dia de começar a semana de aulas e sexta-feira significava que íamos ter dois dias sem aula." (ONDJAKI, 2007, p. 59). O modo de 'medir' o tempo, fora dos ponteiros do relógio, bem ao sabor infantil também é apontado em: "lembro-me disso porque nós sabíamos as horas pelo modo como as sombras invadiam a sala de aula." (ONDJAKI, 2007, p. 65)

Essa percepção do tempo intenso aparece, também, no momento das gargalhadas embaladas em vinte minutos de recreio:

Uns traziam lanche, outros não; uns tinham bola e carrinhos bonitos, outros não; todos vínhamos vestidos com fardamento azul, de modo que no intervalo a escola ganhava uma gritaria toda azul de crianças a quererem aproveitar aqueles vinte minutos de liberdade e maluqueira. [...] No dia seguinte corríamos outra vez. (ONDJAKI, 2007, p. 121, grifos meus) 
E fico a refletir acerca do significado do recreio nas instituições coletivas de educação, o curto espaço de tempo recheado por correria e "gritaria azul". O que seria revelado nesses momentos e o quanto os adultos participam efetivamente desses momentos de parque (ou pátio), ou seria somente um momento de catarse das crianças diante do vivido nas salas de aula?

É nesse ponto que o Menino $\mathrm{N}$ traduz, pela perspectiva aiônica, um dos saberes infantis mais complexos ao olhar adulto: "o tempo para a criança é puro instante, o instante infinito da intensidade, da ocasião, da oportunidade, é o tempo constituído pela simultaneidade, pela experiência da des-memória e da invenção." (CAMPOS; LIMA, 2012, p.151) $)^{15}$

Deste modo, com a vida em pleno movimento, o menino rege um desbravar de sensações e sentimentos estabelecendo com o leitor uma rede de possibilidades de afetar-se, de perceber os segredos lentos do tempo: “O vento voava devagar, as folhas da figueira faziam um ruído que era mais um segredo que um barulho." (ONDJAKI, 2007, p. 64)

A obra Os da minha rua percorre uma crescente dimensão de sentidos, de tal modo que o Menino $\mathrm{N}$ desenvolve uma relação sinestésica de despedida, saudade e lágrimas abafadas. Uma dessas manifestações pode ser experienciada no conto "Um pingo de chuva" (p. 119). A cena, no apartamento dos professores cubanos, ocorre em uma "tarde quase bonita numa cor amarela e castanha que o Sol tinha dentro do apartamento pequeno deles." (ONDJAKI, 2007, p. 121) Nessa despedida, aflora o modo de reinventar das crianças, o modo de arrumar no coração lágrimas e saudades. O quadro finaliza com a afinidade entre despedida com cheiro de amizade cinzenta, o sol e o sentimento das crianças: "Quando chegamos lá em baixo, o Sol já tinha ido embora. O céu queria começar a ficar escuro e, muito atrás de todas as nuvens que podíamos ver, um resto de encarnado vivo iniciou a despedida dele." (ONDJAKI, 2007, p. 123)

Essa atmosfera de despedia, sob um efeito descritivo de sensibilidades, também aparece no último conto "Palavras para o velho abacateiro" (p. 137), em que sucede a transição do Menino N, entre infância e a idade adulta (saída da casa dos pais). A cena desencadeia-se sob uma tempestade que encharca o corpo e a alma do menino: "parei um pouco a deixar a chuva cair sobre a cabeça, fechando os olhos, escutando o ruído que ela fazia cá fora no mundo e dentro de mim também, queria ver quantos pensamentos eu podia inventar - e pensar." (ONDJAKI, 2007, p. 138)

$\mathrm{E}$, diante da perspectiva de viajar, de deixar 'sua rua', o menino entrega-se aos barulhos e cheiros que não poderia dividir com ninguém, porque essa partida "de repente me chegava fora do tempo, num terreno que ia muito além da dor e das lágrimas, num lugar que nenhum escrito meu podia ter conseguido explicar nem nenhuma lágrima conseguiria apagar." (ONDJAKI, 2007, p. 143-144) 
Então, em meio a uma profusão de imagens, transita pelo quarto, pela casa, pelas vivências, pelo tempo/espaço das memórias, pelos silêncios e as fissuras do passado. No quarto, a porta aberta mostra um rasgo de luz que o chama para mais uma experiência sensorial, anunciando mudanças:

entendi que havia uma nesga aberta nos vidros e, por ali, todas as vozes da tarde, da chuva, da trepadeira, das árvores, entravam pelo meu quarto para me dar sinais estranhos que o meu corpo não sabia aceitar, nem a minha cabeça, uma vontade de lágrimas me visitou, cocei a pele da bochecha que era um gesto antigo para falar com as minhas vozes de dentro [...]. (ONDJAKI, 2007, p. 141-142) grifos meus.

O conto celebra um rito entre a infância e a decisão de partir e o Menino $\mathrm{N}$ transforma-se em $\mathrm{N}$, deixa de ser só um menino e leva no baú das memórias suas vivências, experiências de formação: a instituição educativa, a casa, a rua, lesmas no quintal, amigos, cheiros e cores. A árvore, companheira de tantas cenas, velha amiga de tantos segredos, testemunha essa passagem, e $\mathrm{N}$ não reconhece mais as 'palavras' do abacateiro: "não soube mais entender e pode ter sido nesse momento que no corpo de criança um adulto começou a querer aparecer, não sei, há coisas que é preciso perguntar aos galhos de um abacateiro velho." (ONDJAKI, 2007, p. 137)

E ao sabor do tempo aión e da tempestade, $\mathrm{N}$ encerra um ciclo de imagens e memórias evocadas na linguagem apresentadas ao leitor. Resiste em assegurar o lugar da infância, embora nesse dia ela tenha ficado "espremida numa só palavra que quase me doía na boca se eu falasse com palavras de dizer: infância. (ONDJAKI, 2007, p. 145).

\section{FINALIZANDO A CONVERSA...}

A análise literária, aqui prestada considera que o contexto infantil de Os da minha rua foi/é constituído por lampejos de uma possível realidade captada pelo autor, que ao escrever reelabora suas relações com o vivido e com as infâncias, mesmo partindo do lugar de adulto. Assim, a leitura dessa obra ofereceu, em cada conto, centelhas de experiências reveladoras sobre amizades, relações com o mundo, risos, lugares e saberes infantis (des)concertantes.

\section{REFERÊNCIAS BIBLIOGRÁFICAS}

BARBOSA, M. C. S.. Por Amor \& Por Força: Rotinas na Educação Infantil. Campinas, São Paulo, 2000. Tese (Doutorado em Ciências Sociais Aplicadas a Educação). Faculdade de Educação, Universidade Estadual de Campinas. (versão digital)

BARROS, Manoel de. Memórias inventadas: a segunda infância. São Paulo: Planeta, 2006. 1 v. (não paginado) 
CAMPOS, D. F. de; LIMA P. de Moraes. Sous lesailes d'Éroset de Kairos: cartographie des dérives et du hasard dans les récits de Lispector, Sarraute, Gide, Genet et Pompeia. In: POLLOCK, Jonathan (Sous la direction). Pratiques du hasard - Pour un matérialisme de la reencontre. Collection Études: Presses Universitaires de Perpignan, 2012.

CHAUÍ, Marilena de Souza. Convite à filosofia. 10. ed. São Paulo: Ática, 1998.

CHAVES, Rita. O passado presente na literatura africana. Via Atlântica. Faculdade de Filosofia, Letras e Ciências Humanas. Universidade de São Paulo, n. 7. São Paulo: Departamento de Letras Clássicas e Vernáculas, 2004.

FISCHER, Rosa Maria Bueno. Escrita acadêmica: arte de assinar o que se lê. In: COSTA, Marisa Vorraber; BUJES, Maria Isabel Edelweiss (orgs.). Caminhos investigativos III: riscos e possibilidades de pesquisar nas fronteiras. Rio de Janeiro: DP\&A, 2005.

HALBWACHS, Maurice. A memória coletiva. São Paulo: Vértice, 1990.

HONWANA, Luís Bernardo. Nós matamos o cão-tinhoso. São Paulo: Ática, 1980.

KOHAN, Walter Omar. Vida e morte da infância, entre o humano e o inumano. Educação e Realidade. Porto Alegre, v. 35, n. 3, p. 125-138, set./ dez., 2010. Disponível em: http://seer.ufrgs.br/educacaoerealidade/article/ view/13083

LARROSA, Jorge. Pedagogia profana - danças piruetas e mascaradas. Belo Horizonte: Autêntica, 2003.

LEAL, Bernardina. A infância, entre a literatura e a filosofia. In: KOHAN, Walter Omar. (org). Lugares da infância: filosofia. Rio de Janeiro: DP\&A, 2004.

LEJEUNE, Philippe. Le pacte autobiographique. Paris: Seuil, 1975. (Collection Poétique)

LIMA, Patrícia de Moraes. Infância e experiência: as narrativas infantis e a arte-de-viver o cuidado. 2008. Tese (Doutorado em Educação) - Universidade Federal do Rio Grande do Sul. Disponível em: http://hdl. handle.net/10183/15340

OLIVEIRA, Susan Aparecida de; SANTOS, Izabel Cristina da Rosa Gomes dos. Literatura portuguesa III: $9^{\circ}$ período. Florianópolis: UFSC/ CCE/LLV, 2013.

ONDJAKI. Avó Dezanove e o segredo do soviético. São Paulo: Companhia das Letras, 2009. 
. Os da minha rua. Rio de Janeiro: Língua Geral, 2007.

. A bicicleta que tinha bigodes. Rio de Janeiro: Pallas, 2012.

RICOUER, Paul. A memória, a história, o esquecimento. Tradução: Alain François. Campinas, SP: Editora da UNICAMP, 2007.

SKLIAR, Carlos. Pedagogia (improvável) da diferença e se o outro não estivesse aí? Rio de Janeiro: DP\&A, 2003.

SOUSA, Ana Maria Borges de; MIGUEL, Denise Soares; LIMA, Patrícia de Moraes. Módulo 1: gestão do cuidado e educação biocêntrica. Florianópolis: UFSC-CED-Nuvic, 2010.

SOUZA, Solange Jobim e. Infância e linguagem: Bakhtin, Vygotsky e Benjamin. Campinas: Papirus, 1994.

SOUZA, Tania Regina de. A infância do velho Graciliano: memórias em letras de forma. Florianópolis: Ed.UFSC, 2001.

TUAN, Yi-Fu. Espaço e lugar: a perspectiva da experiência. 1930. Tradução de Lívia de Oliveira, São Paulo: Difel, 1983.

Recebido para publicação em 22/05/2014

Aprovado em 25/09/2014

\section{NOTAS}

1 Ondjaki, nascido sob o céu de Luanda no ano de 1977. É prosador e poeta, também escreve para cinema e co-realizou um documentário sobre a cidade de Luanda ("Oxalá cresçam pitangas- histórias de Luanda”, 2006). Sua produção literária pode ser pesquisada no site: http://www.kazukuta.com/ondjaki/ondjaki.html. Informações retiradas de: OLIVEIRA, Susan Aparecida de, SANTOS, Izabel Cristina da Rosa Gomes dos. Literatura portuguesa III: $9^{\circ}$ período. - Florianópolis: UFSC/CCE/LLV, 2013.

2 Vale ressaltar que, em se falando de literaturas africanas (e aqui não exclusivamente de língua portuguesa), o tema infância é recorrente, muito embora na grande maioria apareça em contexto de violência. A proposta aqui busca extrapolar esses contextos, na tentativa de apresentar a infância em sua pluralidade e intensidade.

3 A opção por lugar está intimamente ligada ao conceito de que: "Lugar é uma mistura singular de vistas, sons e cheiros, uma harmonia ímpar de ritmos naturais e artificiais [...]. Sentir um lugar é registrar pelos nossos músculos e ossos." (TUAN, 1983, p. 203).

4 Entrevista "Infância revisitada” por Luís Ricardo Duarte - maio/2008. Disponível em: http://ricardoriso.blogspot.com.br/2008/05/ondjaki-novo-livro-entrevista.html. Acessado em Abril de 2014.

5 Idem a entrevista anterior.

6 Ver pacto de leitura em: LEJEUNE, Philippe. Le pacteautobiographique. Paris: Seuil, 1975. (Collection Poétique)

7 A palavra infâncias, em itálico, remete a minha busca em "ter sempre presente que a infância não é singular, nem é única. A infância é plural: infâncias.” (BARBOSA, 2000, p. $84)$. 
8 Essas crianças circulam as obras: Bom dia camaradas (2006), Os da Minha Rua (2007), AvóDezanove e o Segredo do Soviético (2009) e A Bicicleta Que Tinha Bigodes (2012).

9 Texto original do francês apresentado por minha livre tradução.

10 Texto original do francês apresentado por minha livre tradução.

11 Texto original do francês apresentado por minha livre tradução.

12 Esculú: muito bom, corruptela de “exclusivo”. (ONDJAKI, 2007, p. 158)

13 Excelente, perfeito, bom.

14 Escritor nascido em 1942 sob as estrelas de Moçambique. Teve formação jornalística e apoiou a luta pela libertação do país e esteve preso em 1964, por três anos. O texto Nós Matamos o Cão-Tinhoso publicado (1969) em língua inglesa, obteve divulgação e reconhecimento internacional. Após a independência de Moçambique, Luis Bernardo Honwana desempenhou diversos cargos políticos chegando a ser Ministro da Cultura. Informações retiradas de: http://www.pluraleditores.co.mz/PLE04.asp?area=3\&ID=05

15 Texto original do francês apresentado por minha livre tradução. 